\title{
O PROCESSO DE APRENDIZAGEM DO PROFESSOR DE EDUCAÇÃO FÍSICA ATUANTE EM ACADEMIAS DE GINÁSTICA NO INÍCIO DE CARREIRA ${ }^{1}$
}

\author{
Jairo Antônio Paixão \\ Universidade Federal de Viçosa, Viçosa, Minas Gerais, Brasil \\ Glauber César Cruz Custódio \\ Universidade Federal de Ouro Preto, Ouro Preto, Minas Gerais, Brasil \\ Yuri Windson Santos Barroso \\ Universidade Federal de Ouro Preto, Ouro Preto, Minas Gerais, Brasil
}

\begin{abstract}
Resumo
Foi analisado o processo de aprendizagem do professor com formação em bacharelado em Educação Física, no início de carreira, atuante em academias de ginástica. A partir de um estudo de campo, qualitativo, verificou-se que a formação inicial não proporcionou conhecimentos específicos suficientes para a atuação desse profissional. Dentre as formas de aquisição desses conhecimentos encontram-se contatos com professores formados há mais tempo, leituras de artigos, capítulos de livros e sites que abordam o tema. Essa situação conduz à conclusão de que implementar as experiências vivenciadas pelos acadêmicos nos cursos de bacharelado em Educação Física - ênfase na atuação em academias de ginástica - é uma demanda que merece ser discutida e concretizada nos cursos de formação inicial.

Palavras-chave: Formação Inicial; Educação Física; Bacharelado; Academias de Ginástica.
\end{abstract}

\section{Introdução}

Prevaleceu, até um determinado período, o senso comum, que para ensinar bastava conhecer o conteúdo a ser trabalhado, aproveitando-se, dessa forma, a experiência prática do professor. No entanto, tal concepção tem-se mostrado insuficiente para explicar o processo de ensino-aprendizagem, bem como o das práticas docentes. Os diferentes processos que envolvem a formação inicial de professores tem sido objeto de investigações e, por sua vez, apontam para uma crescente necessidade de se conhecer o que esses sujeitos sabem e o que fazem em seu cotidiano de intervenção profissional (DARLING-HAMMOND; BRANSFORD, 2007).

Pesquisas na área de formação de professores evidenciam que o aprendizado do trabalho docente não passa somente pela formação acadêmico-profissional, na qual são fornecidos conhecimentos teóricos e técnicos (GUARNIERI, 2005; TARDIF, 2011; PIMENTA, 2012). Além dos referidos conhecimentos, as experiências diretas com o fazer do próprio trabalho são fundamentais, pois é nesta instância que serão aprendidos, produzidos e

\footnotetext{
${ }^{1} \mathrm{O}$ presente artigo resultou de uma pesquisa que teve como órgão financiador a Fundação de Amparo à Pesquisa do Estado de Minas Gerais - FAPEMIG no período de março de 2014 a fevereiro de 2015.
} 
articulados saberes práticos essenciais à atuação dos professores ao longo de suas trajetórias profissionais. Em suma, o processo de aprendizagem docente resulta da articulação de diferentes saberes ao longo da trajetória profissional (MONTEIRO, 2001; TARDIF, 2011; PIMENTA, 2012).

Esses saberes foram identificados por Tardif (2011) como profissionais (saberes transmitidos pelas instituições de formação de professores, como por exemplo, escolas normais, faculdades de ciências da educação), disciplinares (saberes que correspondem ao diversos campos do conhecimento e emergem da tradição cultural), curriculares (correspondem aos discursos objetivos, conteúdos e métodos definidos nos programas curriculares de uma instituição de ensino), e por fim, os saberes experienciais (aqueles adquiridos através das experiências práticas diretas com o fazer do próprio campo de intervenção profissional) (TARDIF, 2011; TARDIF; RAYMOND, 2000). A capacidade por parte do professor de dominar, articular e mobilizar tais saberes configura-se condição para sua prática de intervenção cotidiana.

Nessa perspectiva, possuir uma base de saberes na atuação profissional não se traduz tão somente em deter conhecimento, mas também uma compreensão crítica de como esses saberes devem ser adequadamente relacionados com a prática (GRAÇA, 1999). Em outras palavras, trata-se da construção do pensamento prático, que orienta e governa a interpretação e os modos de intervir sobre a realidade. Assim, a capacidade de empregar eficientemente os saberes e habilidades específicas diante de uma situação problema no campo real de intervenção profissional é denominada competência por Perrenoud (1999; 2000).

Dentre as fases que compreendem a trajetória profissional docente, Gonçalves (2007) define como professor iniciante aquele que se encontra entre o primeiro e o quarto anos de atuação. Já Huberman (2007) expõe que o professor está em início de carreira entre o primeiro e terceiro anos de exercício docente. Trata-se de uma fase na qual o sujeito encontrase em intenso processo de aprendizagem profissional. Alguns autores entendem esse período como aquele em que o professor poderá se encontrar em choque com a realidade (HUBERMAN, 2007; GONÇALVES, 2007; SILVA, 1997; GUARNIERI, 2005). Dentre as consequências dessa situação, poderá instalar o sentimento de rejeição e desqualificação pela formação inicial recebida (TARDIF; RAYMOND, 2000). Isso porque, na fase denominada início de carreira, o professor passa por uma série de vivências que poderão resultar em construções positivas ou não acerca da profissão. Por outro lado, trata-se do primeiro contato na condição de professor com a realidade concreta e, portanto, demarca um momento ímpar na trajetória profissional que, por conseguinte, implicará na constituição dos referenciais de ação, crença, intuição e conhecimentos específicos (FERREIRA, 2005).

Outro aspecto que precisa ser considerado, no início de carreira, refere-se à relação que esse sujeito irá estabelecer entre os conhecimentos teóricos e técnicos adquiridos no curso de formação inicial com as vivências práticas no ambiente de intervenção profissional. Em outras palavras, trata-se da necessária articulação entre teoria e prática (CANDAU, 2011). Os estudos na área de formação de professores denunciam a prevalência da dissonância entre teoria e prática nos cursos de formação de professores (SCHÖN, 1992; ZEICHNER, 1993; 2013; GIROUX, 1997; FIORENTINI; SOUSA JÚNIOR; MELO, 2009; PIMENTA; GHEDIN, 2005). Trata-se de uma preocupação presente, desde a década de 1990, nas reformas educacionais, tanto no Brasil como em vários países da América Latina (GENTILE, 2007).

No âmbito da formação inicial em Educação Física, essa dicotomia tornou-se ainda mais evidente a partir da publicação da Resolução CFE 03/87. Essa Resolução normatizava a estruturação dos cursos de graduação plena em Educação Física, os quais deveriam organizarse em termos de currículos mínimos e oferecer uma segunda alternativa de habilitação - o bacharelado - já que, até então, era oferecida apenas a licenciatura plena. Tinha com isso a 
proposição de dois cursos distintos, com campos de intervenção e status próprios na sociedade (BORGES, 2005).

Cumpre destacar que, ainda que o profissional de Educação Física com formação no bacharelado tenha como campo de intervenção a ambiência que se coloca além dos muros da escola, como, por exemplo, academias de ginástica, clubes e outros, parte-se da concepção que ele é, sobretudo, um professor.

Diante do cenário apresentado, e tendo em vista que o processo de aprendizagem docente ganha relevo a partir da formação inicial, o presente estudo teve como objetivo analisar o processo de aprendizagem do professor com formação em bacharelado em Educação Física que se encontra no início de carreira atuante em academias de ginástica.

\section{Metodologia}

Considerando o fenômeno estudado, a trilha científica das ciências humanas e sociais se mostrou a mais indicada para nortear a averiguação dos objetivos estabelecidos. Este estudo se caracteriza como uma pesquisa de natureza qualitativa na qual, de acordo com Minayo (2011), trabalha-se com um universo de significados, motivos, aspirações, crenças, valores e atitudes. Isso corresponde a um espaço mais profundo das relações, dos processos e dos fenômenos, que não podem ser reduzidos à operacionalização de variáveis. Como instrumento de coleta de dados, foi empregada a entrevista semiestruturada, conduzida e fundamentada em estudos de Spradley (1979), que assinala a entrevista como sendo um evento discursivo, o qual, por sua vez, pode ser descrito pelo modo de conduzir alguns diálogos em ocasiões ou encontros sociais. Nessa perspectiva, o autor entende as entrevistas como uma série de conversações entre amigos, dentro das quais o pesquisador suavemente introduz novos elementos para ajudar os informantes a responder como informantes.

A amostra constituiu-se de 17 professores de Educação Física que se encontravam no início de carreira (HUBERMAN, 2007), com formação inicial em bacharelado. Esses sujeitos graduaram em universidades públicas e privadas e atuam em academias de ginástica localizadas em quatro cidades que compõem a região dos Inconfidentes ${ }^{2}$ no estado de Minas Gerais. Como procedimento prévio à aplicação da entrevista, os sujeitos foram informados acerca dos aspectos relativos à pesquisa. Como critérios de inclusão dos sujeitos no grupo amostral foram considerados: professores com formação em bacharelado em Educação Física com até três anos de prática profissional - fase denominada por Huberman (2007) como início de carreira e, após tomarem ciência dos objetivos e natureza da pesquisa, a assinatura do Termo de Consentimento Livre e Esclarecido (TCLE). Consideraram-se como critérios de exclusão os professores que se encontram atuando há mais de três anos, sujeitos sem formação em bacharelado em Educação Física, a recusa da assinatura do TCLE e o não interesse em participar da investigação.

$\mathrm{Na}$ análise dos dados, foi utilizada a técnica de análise de conteúdo que, de acordo com Bardin (2009), refere-se a um conjunto de técnicas de análise das comunicações visando obter, por procedimentos sistemáticos e objetivos de descrição do conteúdo das mensagens, indicadores quantitativos ou não que permitem a inferência de conhecimentos relativos às condições de produção/recepção (variáveis inferidas) dessas mensagens. A autora organiza a análise de conteúdo a partir das fases: pré-análise, exploração do material e tratamento dos resultados, inferência e interpretação. Em consonância com essas fases, após transcrição e análise interpretativa dos dados, estes foram categorizados - por meio de agrupamentos em categorias constituídas por elementos comuns presentes nesses dados - e posteriormente

\footnotetext{
${ }^{2}$ Dentre as cidades que compõem a região dos Inconfidentes em Minas Gerais, a coleta de dados se deu nas cidades de Ouro Preto, Mariana, Itabirito e Catas Altas.
} 
quantificados a partir da frequência de ocorrência em que essas categorias se faziam presentes.

A partir das matrizes curriculares das instituições de ensino superior nas quais os sujeitos da pesquisa concluíram os cursos de bacharelado em Educação Física, foram analisadas a existência ou não da disciplina de musculação, sua carga horária, bem como de outras disciplinas que abordavam conteúdos relacionados às ginásticas de academia. A escolha por essas disciplinas para fins de análise se deu pelo fato de se tratarem de atividades físico-esportivas comumente encontradas em academias de ginástica.

Em consonância com a resolução 466/12 da CONEP, a relação risco-benefício foi baixa, uma vez que houve apenas aplicação da entrevista, previamente agendada, com cada um dos sujeitos e os dados pessoais dos participantes foram omitidos. A pesquisa obteve aprovação junto ao Comitê de Ética em Pesquisa da Universidade Federal de Ouro Preto, ofício CEP Nº 006/2012, de 1 de fevereiro de 2013.

\section{Resultados e discussão}

A discussão desenvolveu-se através da triangulação entre os dados das entrevistas realizadas com os professores participantes da pesquisa, a bibliografia específica utilizada no tema em questão e, também, as posições assumidas pelos autores da investigação em relação ao fenômeno analisado. Dessa forma, foi possível uma discussão aprofundada das categorias de análise que se encontram organizadas na sessão intitulada Formação em Educação Física e a relação com os saberes específicos na atuação em academias de ginásticas no início de carreira profissional que se apresenta a seguir.

\section{Formação em Educação Física e a relação com os saberes específicos na atuação em academias de ginásticas no início de carreira profissional}

De acordo com os dados levantados, a categoria de professores no início de carreira, atuantes em academias de ginástica, encontra-se na faixa etária entre 23 e 32 anos, com média de 25 anos. O tempo de atuação profissional na referida área gira em torno de 1,5 anos, com desvio-padrão de 1,23. A maioria dos participantes $(70,58 \%)$ se formou em instituições de ensino superior pública federal e os demais $(29,42 \%)$ em instituições privadas.

Chama a atenção o fato de os sujeitos da presente pesquisa se tratarem de profissionais com formação inicial em bacharelado em Educação Física, mas por sua vez, não atuarem de forma exclusiva na respectiva área de formação - academias de ginástica. De acordo com os relatos, esses professores desempenham funções que distam completamente do campo da Educação Física como, por exemplo, promoção de eventos e festas infantis, barbearia, gestão de recursos humanos em empresas, dentre outras. Do total de entrevistados, $64,7 \%$ se enquadram na situação descrita. Isso leva a postular que o professor de Educação Física, atuante em academias de ginástica, perfaz longas jornadas em diferentes atividades e funções no mercado de trabalho. Nessa perspectiva, em alguns depoimentos, foram mencionadas cargas horárias que chegavam a 55 horas semanais. Esse quadro decorre da baixa remuneração recebida pelos professores atuantes em academias de ginástica (ESPÍRITOSANTO; MOURÃO, 2008).

No que se refere à formação inicial, buscou-se averiguar se o curso de bacharelado em Educação Física possibitou aos professores os conhecimentos específicos e necessários para sua atuação em academias de ginástica como mostra a Tabela 1. 
Tabela 1 - Formação inicial em Educação Física e os conhecimentos específicos para atuação como professor de academia de ginástica

\begin{tabular}{lc}
\hline & $\begin{array}{c}\text { Bachareis em } \\
\text { A FORMAÇÃO INICIAL EM EDUCAÇo Física }\end{array}$ \\
\cline { 2 - 2 } $\begin{array}{l}\text { não possibilitou conhecimentos específicos (teórico-prático) relacionados } \\
\text { a academias de ginástica }\end{array}$ & 57,1 \\
$\begin{array}{l}\text { possibilitou conhecimentos específicos (predominantemente teórico) } \\
\text { relacionados a academias de ginástica }\end{array}$ & 23,9 \\
$\begin{array}{l}\text { possibilitou conhecimentos específicos (teórico-prático) relacionados a } \\
\text { academias de ginástica }\end{array}$ & 19,0 \\
TOTAL & $\mathbf{1 0 0}$ \\
\hline
\end{tabular}

A Tabela 1 mostra que $57,1 \%$ dos participantes da pesquisa relataram que a formação inicial não lhes proporcionou conhecimentos específicos, tendo em vista a relação teoria e prática para atuarem como professores de academias de ginástica. Ressaltou-se, nas falas dos sujeitos, o fato de não se sentirem preparados para lidarem com conhecimentos específicos que se concretizam nas diferentes atividades físicas, comumente, oferecidas nas academias de ginástica. Esse dado sinaliza elementos para se pensar sobre um possível distanciamento entre as normatizações de princípios e procedimentos oficiais a serem adotados pelas instituições formadoras de ensino superior no país e a sua efetivação nos cursos de formação inicial. Como exemplo, para a formação inicial em Educação Física, as Diretrizes Curriculares Nacionais (Res. n. 07/04) orientam as instituições de ensino superior para a construção de uma formação específica, privilegiando as competências intelectuais que atendam às demandas sociais na área de intervenção (BRASIL, 2004).

Nessa linha de argumentos, vale ressaltar que ainda que a formação do professor seja entendida sobre uma ótica atemporal, que se inicia com a formação inicial e se estende no decorrer de sua trajetória profissional (PIMENTA, 2012), cabe às agências formadoras a responsabilidade pela formação inicial dos sujeitos, com vistas à aquisição de competências profissionais, atentando-se, sobretudo, às mudanças e tendências de um dado campo de intervenção social (MASSA, 2002). No caso dos cursos de bacharelado em Educação Física, os projetos pedagógicos nas instituições de ensino superior devem, sobretudo, articular as unidades de conhecimento na perspectiva da formação ampliada e específica (NUNES; VOTRE; SANTOS, 2012).

Uma questão polêmica que parece prevalecer nas discussões acerca da estruturação curricular dos cursos em Educação Física envolve o núcleo básico de conhecimentos. Alguns advogam pelos conhecimentos eminentemente profissionalizantes de cunho aplicado. Já outros têm se colocado no extremo oposto, defendendo conhecimentos essencialmente acadêmicos e básicos. De acordo com Tani (2007), ambos os conhecimentos se mostram importantes, e devem ser trabalhados de forma equânime com vistas à uma formação sólida de conhecimentos acadêmicos amplos e gerais sobre o objeto de estudo - movimento humano ou cultura do movimento - adquiridos de forma integrada e não fragmentada.

Tendo em vista a atuação profissional dos professores participantes da pesquisa, a Tabela 2 apresenta as atividades desempenhadas por esses sujeitos nas academias de ginástica. 
Tabela 2 - Atividades desenvolvidas nas academias de ginástica

\begin{tabular}{|c|c|}
\hline ATIVIDADES & $\begin{array}{c}\text { Bachareis em } \\
\text { Educação Física }\end{array}$ \\
\hline & $\%$ \\
\hline Musculação & 55,5 \\
\hline Avaliação física & 13,9 \\
\hline Ginásticas & 11,1 \\
\hline Treinamento funcional & 8,7 \\
\hline Hidroginástica & 2,7 \\
\hline Spinning & 2,7 \\
\hline Natação & 2,7 \\
\hline Pilates & 2,7 \\
\hline TOTAL & 100 \\
\hline
\end{tabular}

Dentre as atividades oferecidas pelas academias de ginástica, a musculação aparece como aquela que concentra grande parte $(55,5 \%)$ dos professores. Trata-se de uma situação observada em academias situadas em diferentes pontos do país (SANTOS; KNIJNIK, 2006; TAHARA; SCHWARTZ; SILVA, 2003). Dentre as razões que explicam a predileção da musculação está o fato de a maioria dos alunos que buscam as academias de ginástica consistir de indivíduos fisicamente ativos, situados na faixa entre 18 e 35 anos de idade e que, nomeadamente, objetivam a redução do percentual de gordura corporal e o aumento da massa muscular (HIRSCHBRUCH; CARVALHO, 2008).

Cumpre aqui ressaltar que a análise das matrizes curriculares das instituições em que se formaram esses professores mostrou que a musculação se apresenta como disciplina obrigatória para o curso de bacharelado com carga horária que variava entre 30 a 40 horas. $\mathrm{O}$ mesmo se aplica àquelas disciplinas apontadas pelos entrevistados relacionadas às ginásticas de academias. A distribuição de carga horária teórica e prática, presentes nas matrizes curriculares dos cursos de formação inicial analisadas, apresenta-se de forma equânime, o que, a princípio contradiz a afirmação de uma parcela $(23,9 \%)$ de entrevistados que alegou a predominância de carga horária teórica em relação à prática dos conhecimentos específicos e necessários ao trabalho desenvolvido nas academias de ginástica. Esse argumentos suscitam elementos para se pensar sobre a relação que vem se estabelecendo entre teoria e prática nos cursos de formação inicial.

Em que pese a importância da articulação entre teoria e prática na forma como são abordadas as disciplinas, em tese, o estágio curricular configura-se momento de excelência no qual o acadêmico concretiza tal ação. No entanto, a forma como, geralmente, são estruturados os estágios supervisionados nos cursos de formação inicial somatiza inúmeras fragilidades, não garantindo aos futuros professores uma preparação que os capacite para plena intervenção no ambiente de trabalho (PIMENTA; LIMA, 2012). Essa situação, que coloca em questionamento a eficácia dos estágios supervisionados nos cursos de formação inicial no Brasil, foi apontada por Menga Lüdke ainda no final da década de 1980. A autora denunciou como individualista o caráter da relação que se estabelece entre o aluno estagiário e o profissional que assume o papel de supervisor de campo. Isso porque, o estagiário recebe muito pouca ajuda e orientação do supervisor, inexistindo uma relação que possa assegurar o treinamento e a prática do futuro professor (LÜDKE, 2011).

Conforme mostra a Tabela 3 , os sujeitos, em sua atuação profissional cotidiana, apontaram diferentes dificuldades na fase considerada início de carreira. 
Tabela 3 - Dificuldades percebidas pelos instrutores nas academias

\begin{tabular}{lcc}
\multicolumn{1}{c}{ DIFICULDADES } & $\begin{array}{c}\text { Bachareis em } \\
\text { Educação Física }\end{array}$ \\
$\begin{array}{l}\text { Objetivos específicos dos clientes em decorrência de suas } \\
\text { individualidades e necessidades }\end{array}$ & 63,0 \\
$\begin{array}{l}\text { Insuficiente vivência prática no trato com as atividades desempenhadas } \\
\text { como instrutor de academia de ginástica }\end{array}$ & 11,1 \\
$\begin{array}{l}\text { Reconhecimento profissional por parte dos clientes pelo trabalho } \\
\text { desenvolvido nas academias de ginástica }\end{array}$ & 11,1 \\
$\begin{array}{l}\text { Elevada carga horária de trabalho nas academias de ginástica } \\
\text { Limitação das academias em termos de infraestrutura e aparelhagem } \\
\text { específicas para a realização de determinadas atividades }\end{array}$ & 7,4 \\
TOTAL & $\mathbf{7 , 4}$ \\
\hline
\end{tabular}

Cada vez mais, percebe-se que as academias de ginástica vem se configurando em espaço em que as pessoas buscam por diferentes objetivos como aqueles que se relacionam à estética corporal, saúde e qualidade de vida e ainda processos de reabilitação física (ALVES; TROVO; NOGUEIRA, 2010; FURTADO, 2008). Em contrapartida, essa situação impõe ao professor o domínio de uma gama de competências específicas na condução das atividades de academia oferecidas. Como apresentado na Tabela 3, essa diversidade dos objetivos dos clientes foi percebida por $63 \%$ dos professores no início de carreira como uma das principais dificuldades enfrentadas no dia a dia. Nesse âmbito, Jabur (2011) afirma que o profissional atuante em academias de ginástica se coloca diante de uma situação de elevada e variada exigência de competência especifica, que demandam o conhecimento das necessidades e expectativas dos clientes, que se encontram sob sua orientação.

Ao retomar as análises realizadas nas matrizes dos cursos de formação inicial desses sujeitos, nota-se que as disciplinas que os preparam para a atuação em academias de ginástica se apresentam geralmente com carga horária reduzida, bem como a inserção dos mesmos no mercado de trabalho ocorre, muitas vezes, concomitante e/ou imediatamente após conclusão do curso de bacharelado em Educação Física. Esses fatores contribuem para se entender as dificuldades apontadas pelos professores no início de carreira em academias de ginástica.

Os estudos que abordam a formação inicial de professores compartilham da premissa de que o aprendizado do trabalho docente não se restringe à formação acadêmico-profissional (GUARNIERI, 2005; TARDIF, 2011; PIMENTA, 2012). Os referidos autores completam que as experiências diretas com o fazer do próprio trabalho são fundamentais, pois é nesta instância que serão aprendidos, produzidos e articulados aos saberes práticos outros saberes que foram abordados na formação inicial como os saberes de natureza científica e pedagógica.

Como mostra a Tabela 4, os entrevistados têm diferentes formas de aquisição dos conhecimentos específicos para atuação nas atividades de academia. 
Tabela 4 - Formas de aquisição dos conhecimentos específicos sobre as academia

\begin{tabular}{lc}
\hline \multicolumn{1}{c}{ CATEGORIAS } & $\begin{array}{c}\text { Bachareis em } \\
\text { Educação Física }\end{array}$ \\
\cline { 2 - 2 } & $\%$ \\
\hline Contato com profissionais experientes & 43,9 \\
Referencial teórico (livros, artigos e demais publicações) & 41,8 \\
Participação em congressos, simpósios e cursos de curta duração & 8,9 \\
Outras fontes & 5,9 \\
TOTAL & $\mathbf{1 0 0}$ \\
\hline
\end{tabular}

Com base nos dados da Tabela 4, oberva-se que, dentre as formas de aquisição dos conhecimentos que relacionam-se diretamente às atividades de academia, a categoria mais expressiva foi o contato com professores que detêm maior bagagem de experiência no segmento de academia de ginástica, relatado por $43,9 \%$ dos entrevistados. Isso revela, de forma inequívoca, como afirma Fontana (2010), a significativa contribuição da relação com o outro no compartilhamento das ideias, do fazer, dos conhecimentos muito próprios de um determinado campo de intervenção.

Outra categoria mais citada foi o emprego do referencial teórico como livros, artigos e demais publicações com 41,8 \% das respostas. Aqui evidencia-se o esforço, por parte dos bacharéis em Educação Física iniciantes na carreira, na aquisição de conhecimentos específicos à sua atuação nas academias de ginástica. Trata-se de um caminho adequado no que concerne ao processo de edificação dos saberes relacionados à sua prática profissional, haja vista que se tratam de professores que detêm uma formação inicial na área em questão. Em outras palavras, significa afirmar que se tratam de professores que possuem conhecimentos acadêmicos específicos e necessários à referida área de atuação. Por fim, a participação em congressos, simpósios e cursos de curta duração foi apontada por 8,9\% dos entrevistados como forma de aquisição de conhecimentos relacionados à sua atuação em academias. Essa categoria compreende formas de atualização profissional que convencionou denominar na área da educação de formação docente continuada (PRADA; FREITAS; FREITAS, 2010; GASQUE; COSTA, 2003).

Considerando o ingresso nas academias de ginástica na condição de professores, buscou-se conhecer as sensações dos sujeitos no início de carreira, como mostra a Tabela 5. 
$\underline{\text { Tabela } 5 \text { - Sensações ao ingressar profissionalmente nas academias de ginástica }}$

\begin{tabular}{lc}
\hline \multicolumn{1}{c}{ SENSAÇÕES } & $\begin{array}{c}\text { Bachareis em } \\
\text { Educação Física }\end{array}$ \\
\cline { 2 - 3 } & $\%$ \\
\hline $\begin{array}{l}\text { Insegurança em virtude das responsabilidades assumidas como professor } \\
\text { na academia de ginástica }\end{array}$ & 54,7 \\
$\begin{array}{l}\text { Segurança, credibilidade e confiança por parte dos frequentadores da } \\
\text { academia, pelo fato de serem atendidos por um profissional detentor de } \\
\text { um diploma e registro no Conselho de Educação Física }\end{array}$ & 27,2 \\
$\begin{array}{l}\text { Estar preparado em decorrência das experiências práticas vivenciadas ao } \\
\text { longo da formação inicial }\end{array}$ & 13,6 \\
$\begin{array}{l}\text { Certeza de onde buscar respostas para solucionar as situações problemas } \\
\text { que surgem no ambiente de trabalho }\end{array}$ & 4,5 \\
TOTAL & 100 \\
\hline
\end{tabular}

Na maioria das falas dos participantes, evidenciaram-se implicações de uma formação inicial que ainda não prepara futuros professores para uma atuação plena nas academias de ginástica. Percebe-se claramente, nos depoimentos de 54,7\% dos sujeitos, a insegurança no trato com situações e atividades as quais tiveram ou deveriam ter sido treinados para atuar no referido ambiente de atuação profissional. Com isso, pode-se afirmar a existência de uma lacuna no processo de formação inicial em Educação Física. Essa situação aponta um desdobramento preocupante relatado por $27,2 \%$ dos entrevistados. Trata-se do imaginário popular por parte dos frequentadores da existência de uma relação linear entre o nível de competência, formação inicial e registro no Conselho Federal de Educação Física - este último consiste numa exigência para o profissional bacharel atuar em espaços destinados a essa habilitação como é o caso das academias de ginástica. Na ambiência profissional, apesar da relevância da formação inicial no processo de profissionalização, o diploma não se configura sinônimo de competência e garantia de qualidade nas práticas de intervenção. Por assim dizer, infere-se que o processo de formação docente resulta da articulação de diferentes tipos de saberes a serem vivenciados pelo sujeito ao longo de sua trajetória profissional (TARDIF, 2011; PIMENTA, 2012). A formação inicial não somente fornece as bases de conhecimentos numa determinada área de intervenção profissional, como ainda proporciona informações de como acessar outros conhecimentos e informações correlatas que se fazem necessárias com as demandas que um determinado contexto social ou ambiência de atuação possam requerer.

Outro aspecto que merece destaque é a menção às experiências práticas vivenciadas por $13,6 \%$ dos participantes ao longo do curso de formação inicial que, por sua vez, os conferiram segurança na fase inicial da carreira profissional. Dentre essas experiências destacam-se os estágios curriculares e extracurriculares nas academias de ginástica.

A formação inicial não somente fornece as bases de conhecimentos numa determinada área de intervenção profissional, como ainda proporciona informações de como acessar outros conhecimentos e informações correlatas que se fazem necessárias com as demandas que um determinado contexto social ou ambiência de atuação possam requerer. É unânime, entre os estudos na área de formação de professores, a importância atribuída à necessidade de aproximação entre formação acadêmica e realidade. De acordo com Francisco e Pereira (2004), o estágio constitui uma etapa fundamental na formação do aluno, tendo este o contato com a realidade do seu campo de atuação. Este é um momento da formação em que o 
graduando pode ter diferentes aprendizados, conhecendo melhor sua área de atuação. $\mathrm{O}$ estágio ainda é percebido por Roerch (1999), como a chance que o acadêmico tem para aprofundar conhecimentos e habilidades nas áreas de interesse do aluno. É também nessa oportunidade, que o acadêmico vê realmente a realidade cotidiana e a complexidade da sua futura profissão. Tendo em vista a situação encontrada na realidade concreta, somado ao que apontam estudos como o realizado por Pimenta e Lima (2012), se faz necessario e urgente um repensar na forma como os estágios curriculares se estruturam nos cursos de formação inicial em muitas instituições de ensino superior no país.

\section{Considerações finais}

Diante das constatações obtidas na investigação e considerando as suas limitações metodológicas, é possível afirmar que, ainda que se tratem de professores com formação em bacharelado em Educação Física no início de carreira, prevalece um número considerável de sujeitos que desempenham funções que distam completamente do campo da Educação Física como, por exemplo, promoção de eventos e festas infantis, barbearia, gestão de recursos humanos em empresas, dentre outras. Ao se considerar a opção do sujeito pela Educação Física como campo de intervenção profissional, o investimento financeiro e de tempo na apropriação de conhecimentos que o curso demanda para sua conclusão leva à reflexão sobre fragilidades na inserção desse profissional no início da carreira no mercado de trabalho. Situação que se relaciona diretamente ao contexto socioeconômico que em que o curso de Educação Física se insere atualmente.

Verificou-se que dentre as atividades oferecidas pelas academias de ginástica, a musculação é aquela em que se concentra grande parte dos professores que buscam as academias de ginástica como campo de atuação profissional.

Embora tenham passado por um curso de formação inicial, grande parte dos professores participantes dessa pesquisa relataram que o curso de bacharelado em Educação Física não lhes proporcionou conhecimentos específicos suficientes para atuarem como professores nas academias de ginástica. Com efeito, as análises das matrizes dos cursos de formação inicial em que esses sujeitos se formaram, mostraram que as disciplinas específicas que preparam o futuro professor para a atuar nas diferentes atividades de academias possuem carga horária insuficiente para promover o desenvolvimento de conhecimentos $\mathrm{e}$ competências necessárias a sua atuação nas academias de ginástica.

Tendo em vista essas fragilidades apontadas, os resultados dessa investigação mostram que dentre as formas de aquisição dos conhecimentos necessários pelos professores em início de carreira encontram-se leituras de artigos, capítulos de livros e sites que abordam o tema. No entanto, o destaque recaí na busca de contato com professores formados há mais tempo, atuantes na área específica e que, por sua vez, detêm maior bagagem de experiência.

$\mathrm{O}$ quadro apresentado conduz à conclusão de que implementar as experiências vivenciadas pelos acadêmicos na formação inicial de professores bacharéis em Educação Física para atuar nos diferentes espaços de intervenção profissional, com destaque nesse estudo para as academias de ginástica, é um esforço que merece ser concretizado. Dessa forma, sugerem-se novas investigações sobre o tema, incluindo observação do espaço de intervenção, análise aprofundada de outros elementos presentes nas matrizes curriculares dos cursos de formação. 


\title{
THE LEARNING PROCESS OF THE PHYSICAL EDUCATION TEACHER ACTIVE IN FITNESS CENTERS IN EARLY-STAGE
}

\begin{abstract}
This research aimed to analyze the learning process of a teacher with a Bachelor degree of Physical Education, in early-stage, active in fitness centers. From a qualitative field study, it was found that the initial training did not provide sufficient expertise for the performance of these professionals. Therefore, among the forms of acquisition of this knowledge, were mentioned the contact with trained teachers who are active in that field of professional intervention for longer, readings of articles, book chapters and visits to sites that address the topic. This situation leads to the conclusion that implementing the experiences lived by academics in bachelor degree in Physical Education - with the emphasis in the active teacher in fitness centers - is a demand that deserves to be discussed and implemented in the initial training courses.
\end{abstract}

Keywords: Initial Training; Physical Education; Bachelor; Fitness Centers.

\section{EL PROCESO DE APRENDIZAJE DEL PROFESOR DE EDUCACIÓN FÍSICA ACTIVO EN GIMNASIOS EN EL COMIENZO DE CARRERA}

\begin{abstract}
Resumen
La presente investigación tuvo como objetivo analizar el proceso de aprendizaje del profesor con título de Licenciado en Educación Física, que se encuentra iniciando su carrera, activo en gimnasios. A partir de un estudio de campo cualitativo, se verificó que la formación inicial no proporcionó conocimientos específicos suficientes para el desempeño profesional. Por lo tanto, de entre las formas de adquisición de estes conocimientos fueron encontrados contactos con profesores capacitados hace más tiempo, lecturas de artículos, capítulos de libros y sitios que abordan el tema. Esta situación lleva a la conclusión que implementar las experiencias adquiridas por los estudiantes en los cursos de licenciatura en Educación Física - énfasis en la actuación en gimnasios - es una demanda que merece ser discutida y puesta en práctica en los cursos de formación inicial.
\end{abstract}

Palabras clave: Formación Inicial; Educación Física; Licenciatura; Gimnasios.

\section{Referências}

ALVES, C.; TROVO, C. E.; NOGUEIRA, M.W. A academia de ginástica como lazer para mulheres adultas da cidade de Rio Claro - SP. Revista Mackenzie de Educação Física e Esporte, São Paulo, v. 9, n. 1, 2010.

BARDIN, L. Análise de conteúdo. Trad. Luís Antero Reto e Augusto Pinheiro. 5. ed. Lisboa: Edições 70, 2009.

BRASIL. Conselho Federal de Educação. Resolução n. 3, de 16 de junho de 1987. Diário Oficial n.172, Brasília, 1987.

Conselho Nacional de Saúde. Resolução número 466, de 12 de dezembro de 2012.

Brasília, 2012. Disponível em: <http://www.conselho.saude.gov.br/web_comissoes/conep/index.html>. Acesso em: 04 fev. 2014.

Ministério da Educação/Conselho Nacional de Educação/Câmara de Educação Superior. Resolução n ${ }^{\circ}$ 7, de 31 de março de 2004. Diretrizes Curriculares Nacionais para 
os cursos de graduação em Educação Física. Brasília: MEC, 2004b. Disponível em:< http://portal.mec.gov.br/cne/arquivos/pdf/ces0704edfisica.pdf>. Acesso em: 07 ago. 2014.

CANDAU, V. M. Rumo a uma nova didática. 21. ed. Petrópolis, RJ: Vozes, 2011.

DARLING-HAMMOND, L.; BRANSFORD, J.; (Ed.). Preparing teachers for a changing world: what teachers should learn and be able to do. 2 . ed. The national academy of education : USA, 2007.

ESPÍRITO-SANTO, G.; MOURÃO, L. A auto-representação da saúde dos professores de Educação Física de academias. Revista Brasileira de Ciências do Esporte, Florianópolis, SC, v. 27, n. 3, Jul. 2008. ISSN 2179-3255. Disponível em: <https://rbceonline.org.br/revista/index.php/RBCE/article/view/73/79>. Acesso em: 17 out. 2014.

FERREIRA, L. A. O professor de Educação Física no primeiro ano da carreira: análise da aprendizagem profissional a partir da promoção de um programa de iniciação à docência. 216 p. Tese ( Doutorado em Educação). São Carlos: UFSCar, 2005.

FIORENTINI, D.; SOUSA JÚNIOR., A. J.; MELO, A. G. F. Saberes docentes: um desafio para acadêmicos e práticos. In: GERALDI, C. M. G.; FIORENTINI, D.; PEREIRA, E. M. A. (Org.). Cartografia do trabalho docente: professor(a) pesquisador(a). 4. ed. Campinas (SP): Mercado de Letras, 2009. p. 307-335.

FONTANA, R. A . C. Como nos tornamos professoras?. 3. ed. Belo Horizonte: Autêntica, 2010.

FRANCISCO, C. M.; PEREIRA, A. S. Supervisão e sucesso do desempenho do aluno no estágio, 2004.

FURTADO, R. P. Convívio social, diversão e entretenimento como valor de uso e promessa nas academias de ginástica híbridas. LICERE - Revista do Programa de Pós-Graduação Interdisciplinar em Estudos do Lazer, Belo Horizonte, v. 11, n. 2, 2008.

GASQUE, K. C. G. D.; COSTA, S. M. S. Comportamento dos professores da educação básica na busca da informação para formação continuada. Ciência da Informação, Belo Horizonte, v. 32, n. 3, p. 54-61, 2003.

GENTILE, P. (Org.). Pedagogia da exclusão: crítica ao neoliberalismo em educação. 13. ed Petrópolis: Vozes, 2007.

GIROUX, H. Os professores como intelectuais: rumo a uma pedagogia crítica da aprendizagem. Trad. Daniel Bueno. Porto Alegre: Artes médicas, 1997. p. 157-163.

GONÇALVES, J. A. A carreira das professoras do ensino primário. In: NÓVOA, A. (Org.) Vidas de professores. Portugal: Porto Editora, 2007, p.141- 169.

GRAÇA, A. Conhecimento do professor de educação física. In: Bento, J. O.; R. Garcia, R.; Graça, A. (Org). Contextos da pedagogia do desporto. Lisboa: Livros Horizontes, p. 166$251,1999$.

GUARNIERI, M. R. Aprendendo a ensinar: o caminho nada suave da docência. 2. ed. São Paulo: Autores Associados, 2005. 
HIRSCHBRUCH, M. D.; CARVALHO, J. R. Nutrição Esportiva: uma visão prática. 2. ed. Barueri: Manole, 2008.

HUBERMAN, M. Ciclo de vida profissional dos professores. In: NÓVOA, A. (Org.) Vida de professores. Porto/Portugal: Porto Editora, 2007, p.31-61.

JABUR, M. N. Competências profissionais em educação física: relação entre os fatores de personalidade (e suas facetas) e a competência profissional percebida em professores de academias de ginástica. 2011, 55 p. Tese (Doutorado em Ciências da Psicologia) Universidade de São Paulo, 2011.

LÜDKE, M. O educador: um profissional? In.: Rumo a uma nova didática. 21. ed. Petrópolis, RJ: Vozes, 2011. 73-85.

MASSA, M. Caracterização acadêmica e profissional da Educação Física. Revista Mackenzie de Educação Física e Esporte, São Paulo, v. 1, n. 1, 2002.

MONTEIRO, A. M. F. C. Professores: entre saberes e práticas. Educação \& Sociedade, Campinas, SP, 22 (74), 2001. Disponível em:< http://www.scielo.br/scielo>. Acesso em: 10 set. 2014.

MINAYO, M. C. S. (Org.) Pesquisa Social: teoria, método e criatividade. 30. ed. Petrópolis: Vozes, 2011.

NUNES, M. P.; VOTRE, S. J.; SANTOS, W. O profissional em Educação Física no Brasil: desafios e perspectivas no mundo do trabalho. Motriz, Rio Claro, SP, v. 18, n. 2, p. 280-90, 2012.

PERRENOUD, P. Construir as competências desde a escola. Editora Artmed: Porto Alegre, 1999.

Dez novas competências para ensinar. Porto Alegre: Artmed, 2000.

PIMENTA, S. G. Saberes pedagógicos e atividade docente. 8. ed. São Paulo: Cortez, 2012.

; GHEDIN, E. (Org.). Professor reflexivo no Brasil: gênese e crítica de um conceito. 3. ed. São Paulo: Cortez, 2005.

; LIMA, M. S. L. Estágio e Docencia. 7. ed. São Paulo: Cortez, 2012.

PRADA, L. E. A.; FREITAS, T. C.; FREITAS, C. A. Formação continuada de professores: alguns conceitos, interesses, necessidades e propostas. Revista Diálogo Educacional, Paraná, v. 10, n. 30, 2010.

ROERCH, S.M.A, et al. Projetos de estágio e de pesquisa em administração: guia para estágios, trabalhos de conclusão, dissertações e estudos de caso. 2. ed. São Paulo: Atlas, 1999. 
SANTOS, S. C.; KNIJNIK, J. D. Motivos de adesão à prática de atividade física na vida adulta intermediária. Revista Mackenzie de Educação Física e Esporte, São Paulo, v. 5, n. $1,2006$.

SCHÖN, D. Formar professores como profissionais reflexivos. In: NÓVOA, A. Os professores e sua formação. 3. ed. Lisboa: D. Quixote, 1997. p. 81-91.

SILVA, M. C. M. O primeiro ano de docência: o choque com a realidade. In: ESTRELA, Maria T. (Org.) Viver e construir a profissão docente. Portugal: Porto Editora, 1997, p.51-80.

SPRADLEY, J. P. The ethnographic interview. Florida: Harcourt Brace Jovanovich, 1979.

TAHARA, A. K.; SCHWARTZ, G. M.; SILVA, K. A. Aderência e manutenção da prática de exercícios em academias. Revista Brasileira de Ciência e Movimento, Brasilia, v. 11, n. 4, p. 7-12, 2003.

TANI, G. Avaliação das condições do ensino de graduação em educação física: garantia de uma formação de qualidade. Revista Mackenzie de Educação Física e Esporte, São Paulo, v. 6, n. 2, 2007.

TARDIF, M. Saberes docentes e formação profissional. 16. ed. Petrópolis: Vozes, 2011.

TARDIF, M.; RAYMOND, D. Saberes, tempo e aprendizagem do trabalho no magistério. Revista Educação e Sociedade, Campinas,SP, v. 21, n. 73, p. 209-244, dez. 2000.

ZEICHNER, K. M. A formação reflexiva de professores: ideias e práticas. Lisboa: Educa, 1993. p.12-52.

Políticas de formação de professores nos Estados Unidos: como elas afetam vários países do mundo. Belo Horizonte: Autêntica, 2013.

Recebido em: 22/04/2015

Revisado em: 16/12/2015

Aprovado em: 09/03/2016

Endereço para correspondência:

jairopaixao2004@yahoo.com.br

Jairo Antônio Paixão

Universidade Federal de Santa Catarina

Avenida Peter Henry Rolfs, s/n

Campus Universitário

Viçosa - MG, 36570-900 